\title{
Espécie nova de Xestoblatta (Blattaria, Blattellidae) do Estado de Santa Catarina, Brasil
}

\author{
Sonia Maria Lopes \& Edivar Heeren de Oliveira
}

Departamento de Entomologia, Museu Nacional, Universidade Federal do Rio de Janeiro, Quinta da Boa Vista, São Cristóvão, 20940-040 Rio de Janeiro, Brasil. CNPq/FAPERJ (sonialf@acd.ufrj.br)

\begin{abstract}
New species of Xestoblatta (Blattaria, Blattellidae) from the State of Santa Catarina, Brazil. Xestoblatta insularis sp. nov. is described based on genital plates, male genital structures and modification on seventh abdominal tergite. Xestoblatta Hebard, 1916 is recorded for the first time to southern Brazil.
\end{abstract}

KEYWORDS. Xestoblatta, Neotropics, new species, taxonomy.

RESUMO. Xestoblatta insularis sp. nov. é descrita com base nas placas genitais, estruturas genitais do macho e na modificação do sétimo tergito abdominal. Xestoblatta Hebard, 1916 é registrado pela primeira vez no sul do Brasil.

PALAVRAS-CHAVE. Xestoblatta, Neotrópico, espécie nova, taxonomia.

O gênero Xestoblatta Hebard, 1916 está representado no Brasil por dezoito espécies, sendo dez para a região norte, duas para região nordeste, três para região sudeste e três para região centro-oeste.

As espécies caracterizam-se pelo porte médio a grande e pelo campo marginal da tégmina com coloração amarelo-pálida.

HEBARD (1916) definiu o gênero como monofilético e caracterizou-o por apresentar o disco do pronoto sem sulcos, tégminas e asas muito desenvolvidas, setores discoidais da tégmina longitudinais, veia discoidal da asa bifurcada, veia ulnar com ou sem ramos incompletos, triângulo apical grande e distinto, margem ântero-ventral do fêmur anterior com uma série de espinhos subiguais, seguidos por outra série de tamanho menor e decrescente em direção ao ápice e com três espinhos apicais; presença ou não de modificação tergal no abdome no sétimo segmento; fêmures médio e posterior com numerosos espinhos robustos e um espinho genicular simples e alargado; arólios presentes; pulvilos nos quatro segmentos; unhas simétricas e simples.

GURNEY (1939) agrupou as espécies, com base na presença de modificação tergal do abdome em $X$. surinamensis Bruijning, 1959, X. zetecki Gurney, 1939, X. ecuadorana Gurney, 1939, X. micra Hebard, 1916, X. peruana (Saussure, 1862), X. potrix (Gurney, 1939).

Com base em material procedente do sul do Brasil, descreve-se mais uma espécie desse grupo.

\section{MATERIAL E MÉTODOS}

A observação das placas e peças genitais foi feita através da retirada da parte final do abdome dos exemplares, utilizando-se técnicas tradicionais para dissecção (LOPES \& OliveIRA, 2000). A designação das peças genitais e a classificação taxonômica foram baseadas nos conceitos propostos por McKITTRICK (1964).

O material foi coletado em Nidularium inoccentii
[Bromeliaceae] na Unidade de Conservação Ambiental do Desterro (UCAD), Santa Catarina e tombado no Museu Nacional, Universidade Federal do Rio de Janeiro (MNRJ).

\section{Xestoblatta insularis sp. nov.} (Figs. 1-11)

Etimologia. O nome da espécie refere-se à localidade onde foram coletados os exemplares.

Coloração geral castanho-clara brilhante (Fig. 1).

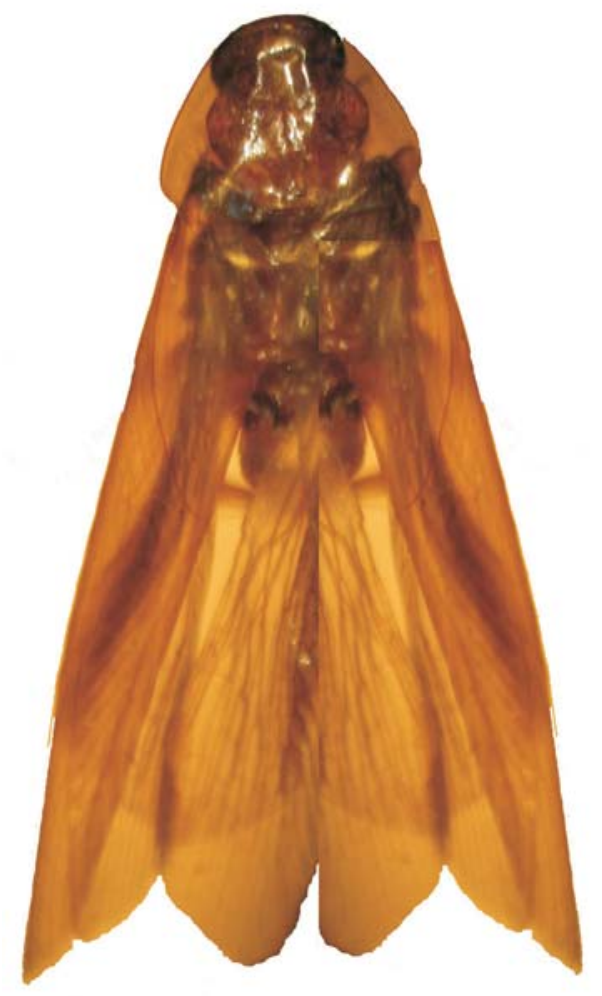

Fig. 1. Xestoblatta insularis sp. nov., holótipo ơ, habitus, $19 \mathrm{~mm}$. 
Cabeça castanha; artículo apical do palpo maxilar, nuances na fronte e no clípeo castanho-escuros; olhos negros; antenas claras com tomentosidade dourada. Pronoto transparente com disco central castanho-leitoso. Pernas castanho-claras com ponto de inserção dos espinhos castanho-escuros, quase negros. Tégminas e asas transparentes e brilhantes.

Dimensões em mm, o. Comprimento total:19,0; comprimento do pronoto: 4,0 ; largura do pronoto: 5,0 ; comprimento da tégmina: 16,5; largura da tégmina: 5,0.

Cabeça (Fig. 2) subtriangular, olhos pequenos, espaço interocular amplo, com medida aproximadamente igual à área que separa as bases das antenas; antenas longas, atingindo o ápice do abdome; palpos maxilares desenvolvidos, quinto artículo dilatado, menor que o quarto, ambos menores que o terceiro.

Pronoto (Fig. 3) convexo, triangular, com ápice arredondado, base levemente angular; abas laterais amplas e defletidas, com disco central bem demarcado e sem sulcos. Pernas longas e espinhosas; fêmur anterior com duas séries de espinhos robustos e espaçados na face ântero-ventral, sendo a segunda série decrescente, terminando em um pré-apical de tamanho médio e dois apicais grandes; face póstero-ventral com cinco espinhos grandes e espaçados, sendo um apical; fêmures médio e posterior com disposição semelhante dos espinhos em
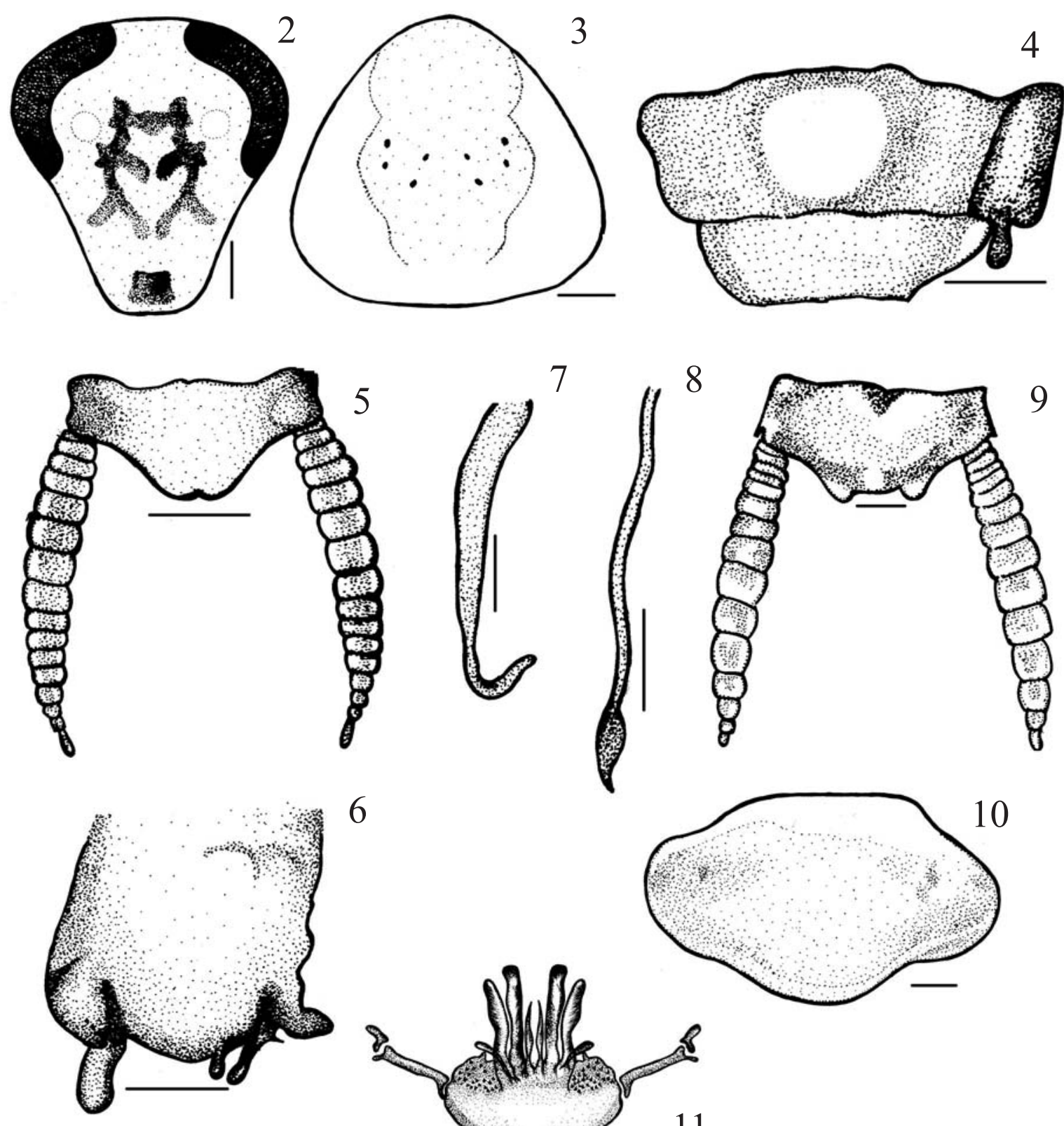

6
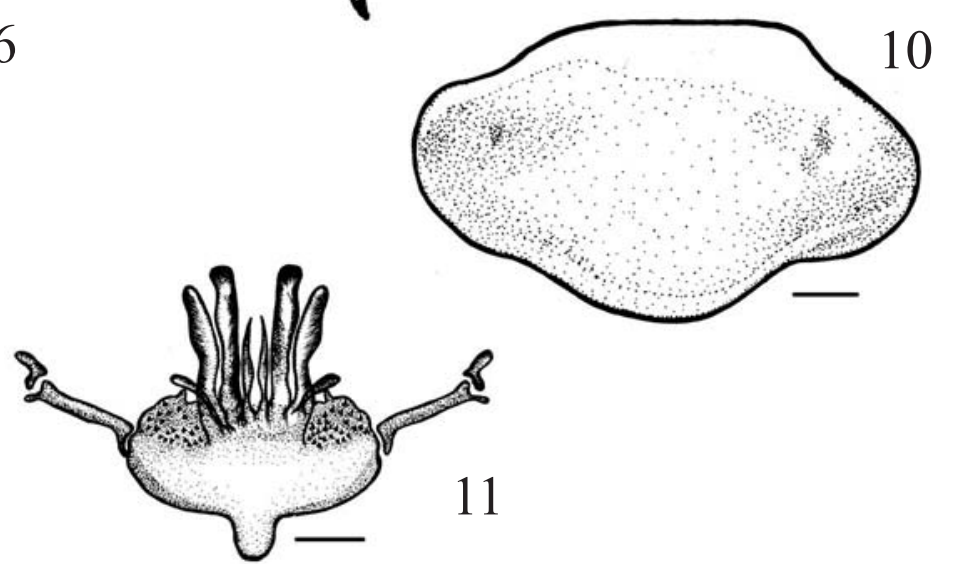

Figs. 2-11. Xestoblatta insularis sp. nov. 2-8, holótipo ơ: 2, cabeça, ventral; 3, pronoto, dorsal; 4, modificação tergal no sétimo segmento, dorsal; 5, placa supra-anal, dorsal; 6, placa subgenital, ventral; 7, falômero esquerdo, dorsal; 8, esclerito mediano, dorsal; 9-11, parátipo ఢ.: 9, placa supra-anal, dorsal; 10, placa subgenital, ventral; 11, válvulas, dorsal. Figs. 2, 7-11 Escala, 0,5 mm; Figs. 3-6 Escala, 1mm. 
ambas as faces ventrais, com sete espinhos grandes, sendo um apical; presença de espinho genicular; pulvilos e arólios presentes, pouco desenvolvidos; unhas simétricas e simples. Tégminas desenvolvidas, longas, estreitas e convexas, ultrapassando o ápice dos cercos; campo marginal amplo e defletido; campo escapular oblíquo, com nove ramos simples, seguindo com ramos bifurcados para o ápice; campo discoidal longitudinal e campo anal amplo e alongado, com cinco veias axilares. Asas desenvolvidas, com setor costal apresentando o ápice dos seis ramos basais da veia radial com leve dilatação; triângulo apical ou intercalar desenvolvido; campo anal dobrado em leque.

Abdome do macho com modificação tergal no sétimo segmento, em forma de uma depressão arredondada e evidenciada, com projeções laterais em forma de uma prega voltada para o interior do segmento (Fig. 4). Placa supra-anal projetada entre os cercos, com leve reentrância mediana no ápice (Fig. 5). Cercos longos. Placa subgenital assimétrica, com o bordo látero-apical direito expandido; estilos diferenciados em forma e tamanho e presença de um estilo acessório pequeno próximo ao estilo direito (Fig. 6). Falômero esquerdo em gancho afilado e pouco desenvolvido (Fig. 7). Esclerito mediano alongado, com o ápice foliáceo (Fig. 8).

Dimensões da $\subsetneq$ em mm. Comprimento total: 16,5 ; comprimento do pronoto: 4,0; largura do pronoto: 5,5 ; comprimento da tégmina: 14,0; largura da tégmina: 4,0.

A fêmea diferencia-se do macho pela ausência de modificação tergal. Placa supra-anal projetada entre os cercos com duas projeções apicais; cercos desenvolvidos (Fig. 9). Placa subgenital simétrica e elipsóide (Fig. 10). Complexo valvular com par de válvulas I e II diferenciadas em tamanho e valvíferos reduzidos (Fig. 11).

Material-tipo. Holótipo ơ, BRASIL, Santa Catarina: Florianópolis, UCAD-284, 19.I.2004, coletada em N. innocentii, Josefina Steiner \& Anne Zillikens cols. Parátipo $\$$, mesma procedência, UCAD-289, 04.II.2004, Josefina Steiner \& Anne Zillikens cols.

Discussão. A espécie apresenta modificação tergal típica para o gênero, diferenciando-se das demais espécies de Xestoblatta pela configuração da placa subgenital, estilos e estruturas da genitália masculina.

\section{REFERÊNCIAS BIBLIOGRÁFICAS}

Gurney, A. B. 1939. A revision of the neotropical genus Xestoblatta Hebard (Orthoptera; Blattidae; Pseudomopinae). Proceedings of the Entomological Society of Washington 41(4):97-128.

Hebard, M. 1916. Studies in the group Ischnopterites (Orthoptera, Blattidae, Pseudomopinae). Transactions of the American Entomological Society 42:337-383.

Lopes, S. M. \& Oliveira, E. H. 2000. Espécie nova de Eublaberus Hebard, 1919 do Estado de Goiás, Brasil e notas sobre E. marajoara Rocha e Silva-Albuquerque, 1972 (Blaberidae, Blaberinae). Boletim do Museu Nacional, Nova Série, Zoologia 433:1-5.

McKitTrick. F. A. 1964. Evolutionary studies of cockroaches. Cornell University Agricultural Experiment Station Memoirs 389:1-197.

Recebido em março de 2006. Aceito em abril de 2007. ISSN 0073-4721

Artigo disponível em: www.scielo.br/isz 